\title{
Evaluation of Hydrogen-Assisted Cracking Susceptibility in Grade T24 Steel
}

\author{
The susceptibility to hydrogen-assisted cracking of Grade T24 steel base metal \\ and the simulated CGHAZ was evaluated using a delayed hydrogen cracking test
}

\author{
BY X. FENG, J. M. STEINER, B. T. ALEXANDROV, AND J. C. LIPPOLD
}

\begin{abstract}
The delayed hydrogen cracking test was performed to evaluate the hydrogen-assisted cracking (HAC) susceptibility of Grade T24 steel base metal and the simulated coarsegrained heat-affected zone (CGHAZ). The base metal did not fail after testing for up to $672 \mathrm{~h}$. In contrast, the CGHAZ sample failed after about $2 \mathrm{~h}$ when charged from all four sides, and $4 \mathrm{~h}$ when charged only from the internal diameter (ID) surface. The higher HAC resistance of the base metal compared to the CGHAZ was due to the microstructure difference. The tempered bainitic-martensitic microstructure in the base metal was more resistant to HAC compared to the untempered martensite microstructure in the CGHAZ. Fractography analysis indicated the decarburized zone on the ID surface delayed the development of the critical hydrogen concentration in the CGHAZ, thus improving the HAC resistance. The HAC cracking initiated with an intergranular fracture, then transitioned to quasi-cleavage and microvoid coalescence. The fracture behavior was explained using Beachem's model.
\end{abstract}

\section{KEYWORDS}

- Delayed Hydrogen Cracking Test • Grade T24 Steel

- Hydrogen-Assisted Cracking • Fracture Analysis

- Microstructure

\section{Introduction}

Grade T24 steel has been developed as a material that can be used without preheat and postweld heat treatment in thin-wall structures (Ref. 1). It was developed based on a modification in the chemical composition of Grade 22 steel (Ref. 2). It has wide applications in ultra-supercritical boilers (Ref. 3). Many researchers have investigated the welding process and properties of this steel (Refs. 4-8).
Compared to the conventional Grade 22 steel, Grade T24 steel has a reduced carbon content for improved weldability and is microalloyed with vanadium, titanium, and boron for precipitation strengthening with fine $M X$-type $(M=V$, $\mathrm{Ti} ; \mathrm{X}=\mathrm{C}, \mathrm{N}$ ) carbides and/or carbonitrides.

Grade T24 steel is usually delivered in the normalized and tempered condition with a tempered bainitic-martensitic microstructure (Ref. 9). Hardness values lower than $350 \mathrm{HV}$ are required for power generation applications with Grade T24 steel welds (Ref. 10). Recently, cracking in the welds of the water-wall panels made of Grade T24 steel has been reported in a number of newly constructed power plants in Europe after a few hundreds of hours of operation. The nature of cracking in these instances is not yet clear, but it has been speculated to be a form of stress corrosion cracking (SCC) (Refs. 11-14). Meanwhile, the presence of magnetite on the crack surface was confirmed. Therefore, hydrogen-assisted cracking (HAC) initiated by the Schikorr reaction could also be a contributing factor. This kind of failure mechanism operates with the simultaneous presence of a susceptible microstructure, high residual stress, and exposure to an aqueous and/or corrosive environment where hydrogen can be concentrated. The occurrence of $\mathrm{HAC}$ is not uncommon in high-strength steels (Refs. 15-19). Researchers have reported Grade T24 steel is susceptible to SCC (Ref. 20), but its susceptibility to HAC has not yet been fully understood.

As a result, in this study, the delayed hydrogen cracking test (DHCT) was used to evaluate the Grade T24 steel HAC susceptibility, which is caused by the Schikorr reaction during service. This test consisted of simultaneous electrolytical charging with hydrogen and loading with a constant tensile stress (below the steel yield strength) on the tested sample (Ref. 21). The time to failure was used as a criterion to evaluate the HAC susceptibility. Both the Grade T24 base metal and simulated coarse grain heat-affected zone (CGHAZ) were tested. 

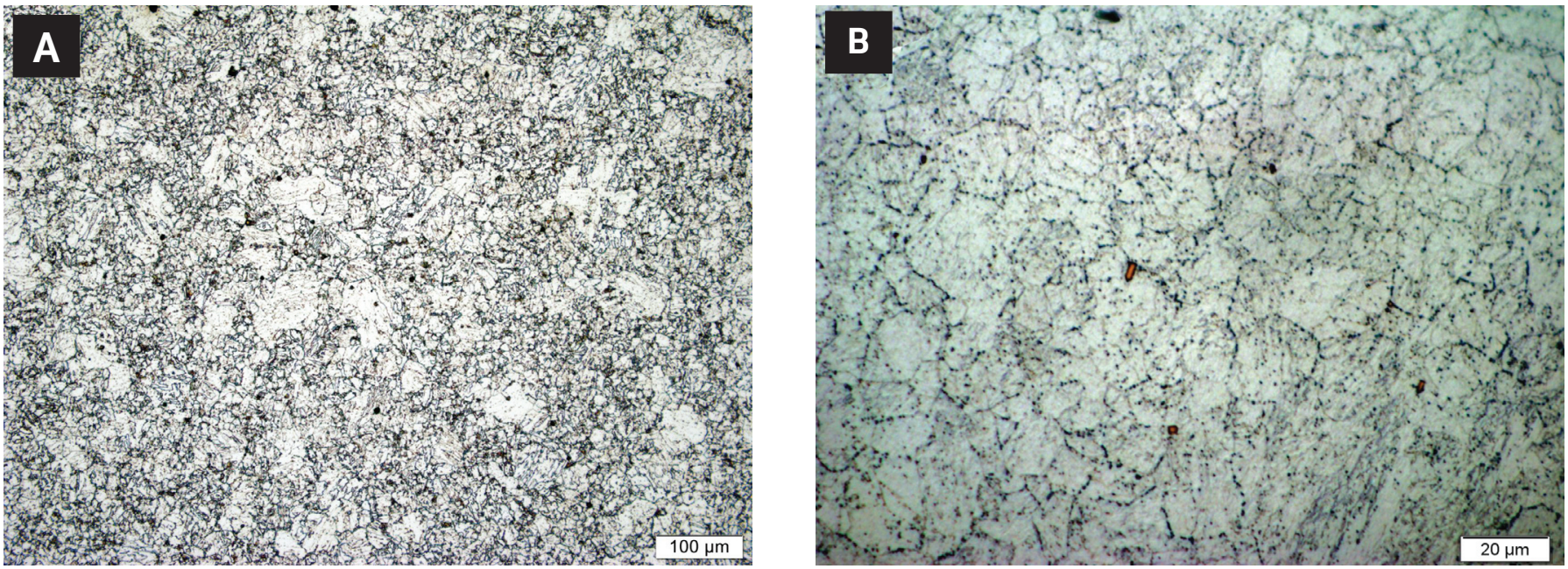

Fig. 1-Microstructure of the Grade T24 steel base metal: A - Tempered bainite and martensite; B - Ti(C, N) in the base metal.
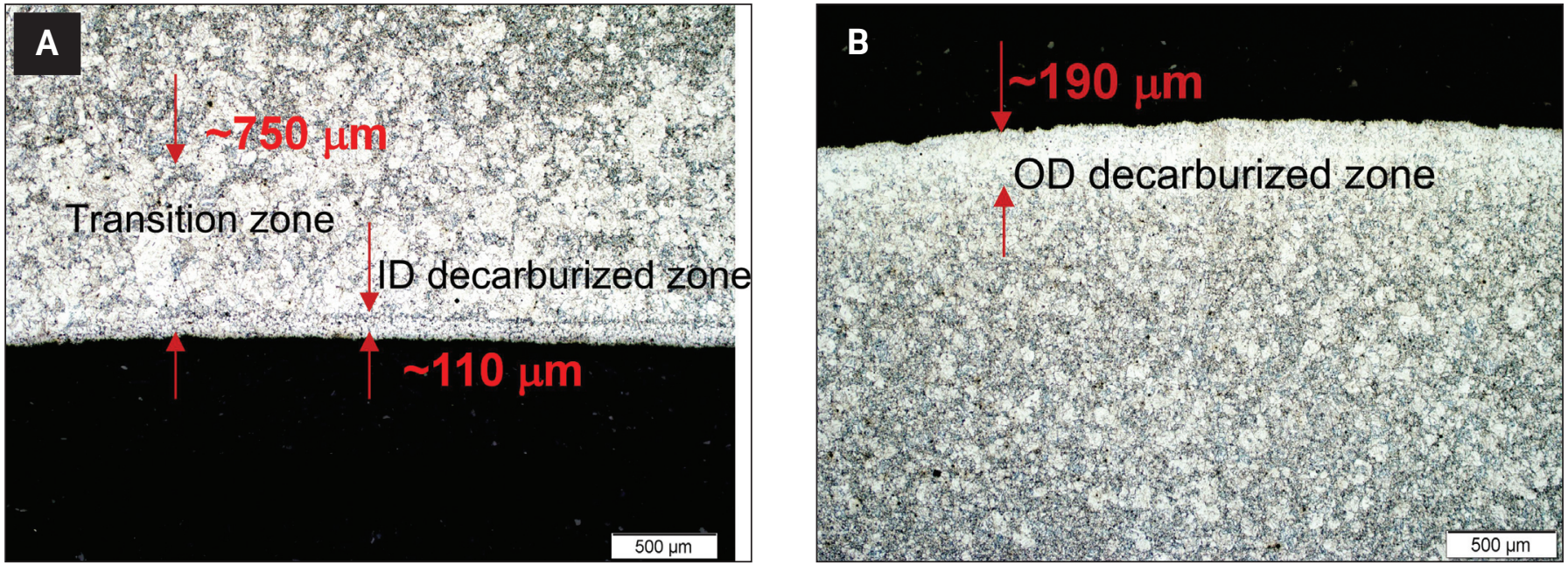

Fig. 2 - Decarbonized zones on the ID and OD surfaces of the Grade T24 tube: A - ID side; B - OD side.

\section{Materials and Experimental Procedures}

\section{Base Metal}

The Grade T24 steel base metal used in this study was a hot-rolled tube with an outside diameter (OD) of $44.5 \mathrm{~mm}$ and a wall thickness of $7.1 \mathrm{~mm}$. The chemical composition and mechanical properties of the Grade T24 steel are shown in Table 1. The tube was in the as-delivered condition with a tempered bainitic-martensitic microstructure (Fig. 1A) and a microhardness of $215 \mathrm{HV}_{0.1}$. The gold-colored cuboidal particles (Fig. 1B) observed in the base metal were identified as $\mathrm{Ti}(\mathrm{C}, \mathrm{N})$ using the energy dispersive spectroscopy in the scanning electron microscope (SEM).

Narrow decarburized layers were present at the tube OD and internal diameter (ID) surfaces. Figure 2 shows the OD and ID decarburized layers, which were measured to be $\sim 190$ and $\sim 110 \mu \mathrm{m}$, respectively. A transition zone, which is the light-etched area extending beyond the decarburized

Table 1-Chemical Composition and Mechanical Properties of the Grade T24 Steel

Chemical Composition (wt-\%)

$\begin{array}{ccccccccccccc}\mathrm{C} & \mathrm{Mn} & \mathrm{P} & \mathrm{S} & \mathrm{Si} & \mathrm{Cr} & \mathrm{Mo} & \mathrm{Ti} & \mathrm{V} & \mathrm{B} & \mathrm{N} & \mathrm{Al} \\ 0.08 & 0.56 & 0.012 & 0.004 & 0.26 & 2.47 & 0.98 & 0.09 & 0.24 & 0.0056 & 0.009 & 0.015\end{array}$

Mechanical Properties 


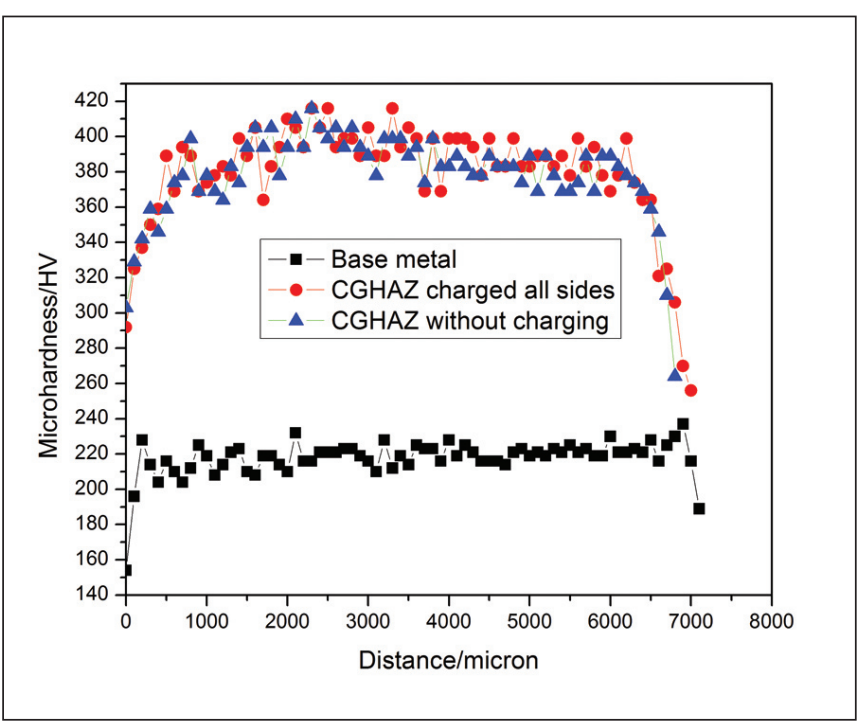

Fig. 3-Microhardness of the cross section of the base metal and simulated CGHAZ.

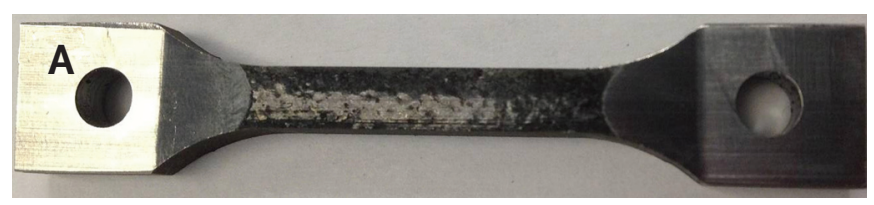

B
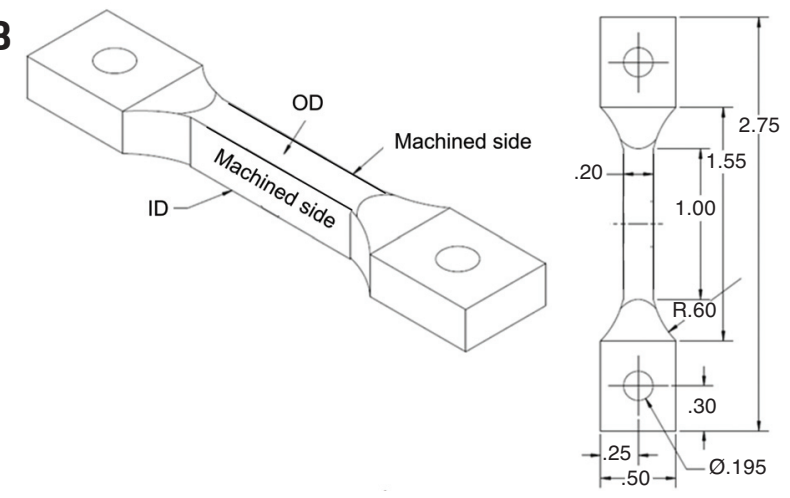

Fig. 4 - Geometry of the DHCT sample: A - Machined sample; $B$ - schematic drawing of the sample.
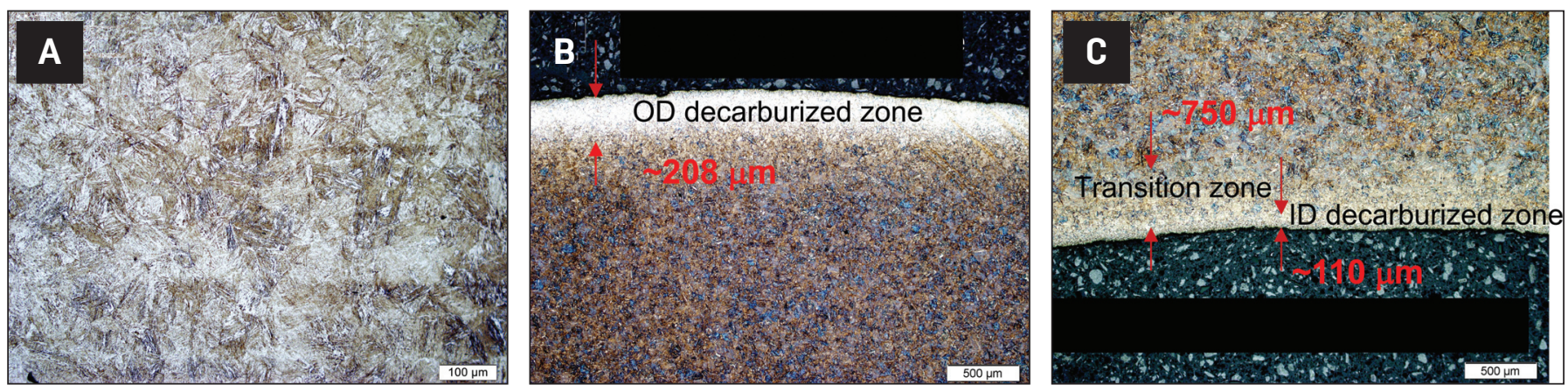

Fig. 5 - Microstructure of the simulated CGHAZ: A - Bulk; B - OD side; $C-I D$ side.

zone, was revealed at the ID side. The transition zone was measured to be $\sim 750 \mu \mathrm{m}$. Figure 3 shows the microhardness along the traverse direction. The microhardness in the CGHAZ was much higher than that in the base metal because of the formation of martensite.

Dog-bone-shaped test samples were extracted from the tested tube. Figure 4 shows the geometry of the test samples. The longitudinal axis of the samples was parallel to the tube axis. The gauge section had a decarburized microstructure at the OD and ID surfaces, as well as a normalized and tempered microstructure at the other two machined-side surfaces.

\section{Simulated CGHAZ}

Dog-bone samples with simulated CGHAZ were produced using the Gleeble ${ }^{\mathrm{TM}} 3800$ thermal-mechanical simulator. The temperature was controlled with a type-K thermocouple, which was welded to the sample at the midsection. The samples were heated to a peak temperature of $1350^{\circ} \mathrm{C}$ at a linear rate of $100^{\circ} \mathrm{C} / \mathrm{s}$ and then free-cooled to room temperature. The cooling time from $800^{\circ}$ to $500^{\circ} \mathrm{C}\left(\mathrm{t}_{8 / 5}\right)$ in these samples varied between 13.4 and $13.9 \mathrm{~s}$. The simulations were conducted in a vacuum of $10^{-3}$ torr to limit surface oxidation and avoid thermocouple detachment. The CGHAZ mi- crostructure was a mixture of bainite and martensite (Fig. 5A) with a microhardness in the range of 370 and $420 \mathrm{HV}_{0.1}$ in the bulk of the tube wall. The OD and ID decarburized layers were measured to be $\sim 208$ and $\sim 110 \mu \mathrm{m}$, respectively Fig. 5B, C. A transition zone that had a width of $\sim 750 \mu \mathrm{m}$ was revealed at the ID.

\section{DHCT Sample Preparation}

The gauge section was lightly ground with 400- then 800 grit sandpaper to remove any surface contamination and oxides. After grinding, the samples were further cleaned in an ultrasonic cleaning bath. Following this, the area intended for electrolytic charging with hydrogen was marked on the sample, and fingernail polish was applied to cover all remaining surfaces adjacent to this area. When the fingernail polish completely dried, the sample was inserted into the extension rods, and all surfaces not intended to be charged were coated in Plasti Dip ${ }^{\circledR}$ — Fig. 6.

\section{DHCT}

The DHCT applied a constant tensile load to the test sample, which was simultaneously subjected to electrolytic charging with hydrogen. The time to failure under these 

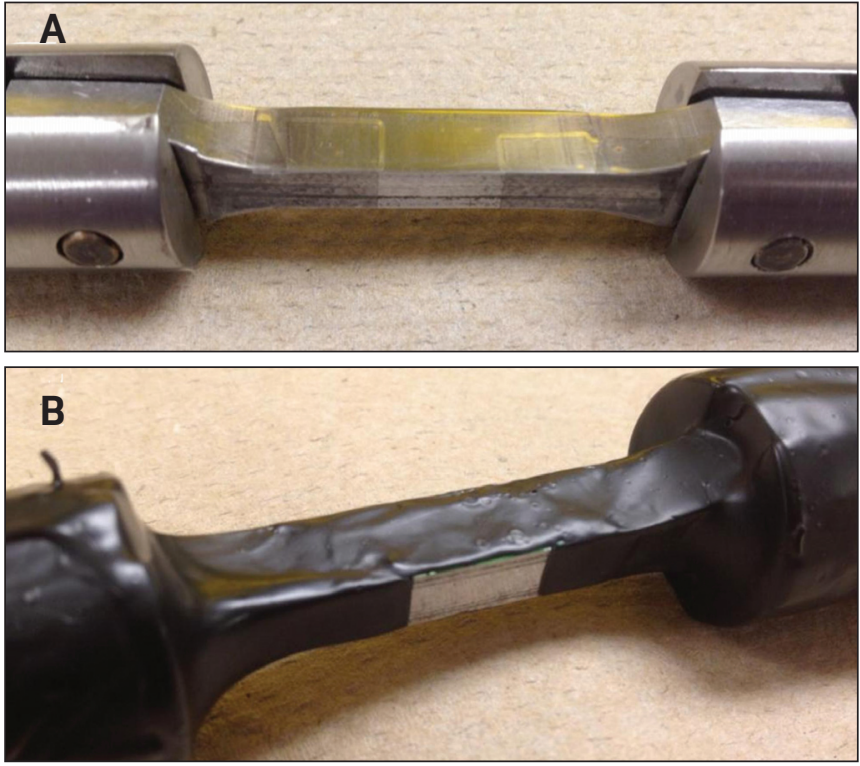

Fig. 6 - Samples prepared for the DHCT: A - Before coating with Plasti Dip; B - after coating with Plasti Dip.

testing conditions was used as a criterion for ranking susceptibility to HAC. A longer time to failure indicated a greater resistance to HAC. The test conditions used in this study included the following: 1) The tensile loading stress was $90 \%$ of the base metal yield strength; 2 ) the charging current density was $10 \mathrm{~mA} / \mathrm{cm}^{2}$; and 3) the electrolyte was made of $27.5 \mathrm{~mL} \mathrm{H}_{2} \mathrm{SO}_{4}$ in 9500 -mL distilled water with the addition of $0.5-\mathrm{g} \mathrm{Na}_{2} \mathrm{~S}_{2} \mathrm{O}_{3}$. The solution's $\mathrm{pH}$ was approximately 1.22. The sodium thiosulfate acted as a barrier to recombination of the atomic hydrogen into hydrogen gas. Figure 7A shows the DHCT frame. The arm gave a 10:1 ratio for the hanging weights. The linear variable displacement transducer was positioned at the end of the arm to measure the sample displacement and detect failure. The polypropylene cell is shown in Fig. 7B. The alligator clip at the top connect-
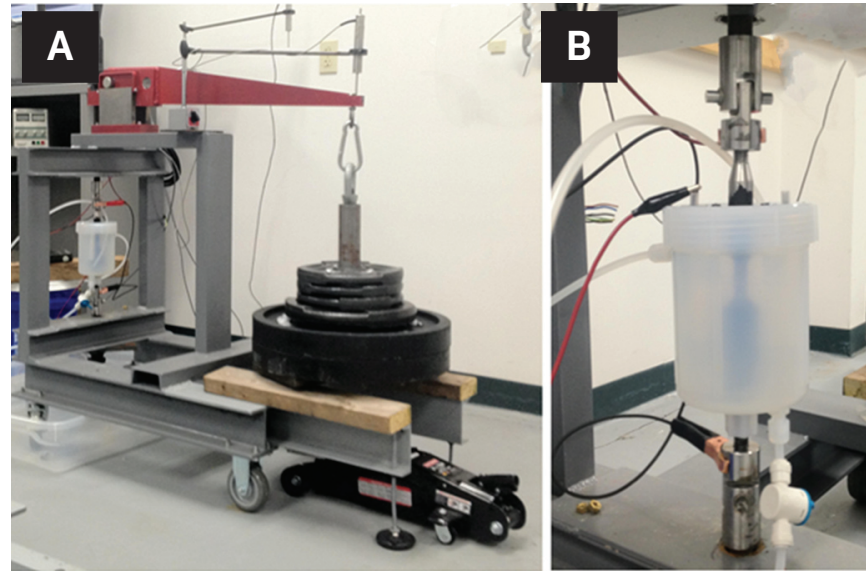

Fig. 7 - The DHCT equipment: A - Test frame; B polypropylene cell.

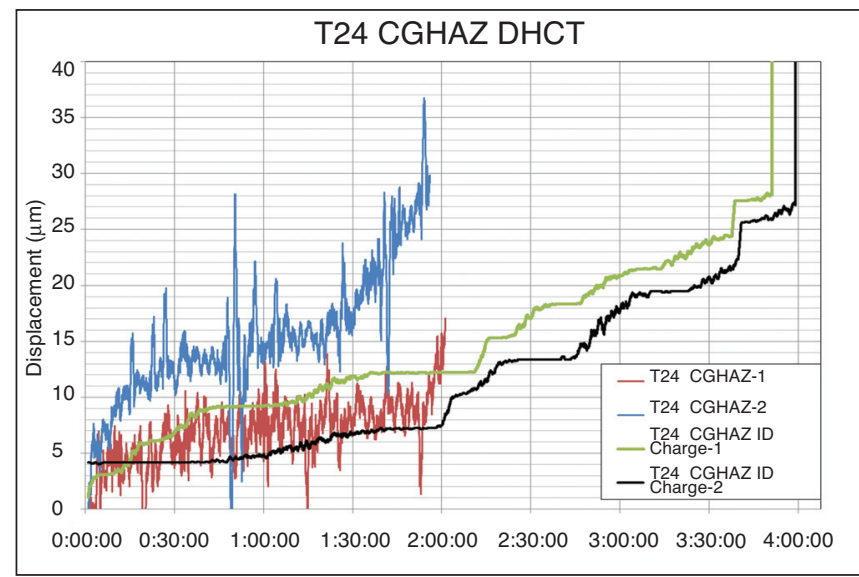

Fig. 8 - The displacement of the tested samples as a function of time.

ed the power supply to the platinum coil surrounding the sample. The two clamps attached to the clevises completed

Table 2 - Summary of the DHCT Results

Sample

T24 CGHAZ 1

T24 CGHAZ 2

T24 CGHAZ ID 1

T24 CGHAZ ID 2

T24 CGHAZ no tensile load

T24 CGHAZ no hydrogen charging

T24 base metal 1

T24 base metal 2

Time to Failure, h:min

2:01

$1: 56$

3:51

3:59

Cracks found after $48 \mathrm{~h}$ charging

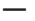

$-$
Note

Circumferentially charged, $10-\mathrm{mm}$-wide charged area

Circumferentially charged, $10-\mathrm{mm}$-wide charged area

ID charged, 10-mm-wide charged area

ID charged, 10-mm-wide charged area

ID charged, 10-mm-wide charged area, no tensile load

Did not fail in $264 \mathrm{~h}$,

tensile load without hydrogen charging

Did not fail in $672 \mathrm{~h}$, circumferentially charged, 5-mm-wide charged area

Did not fail in $266 \mathrm{~h}$,

ID charged, 10-mm-wide charged area 

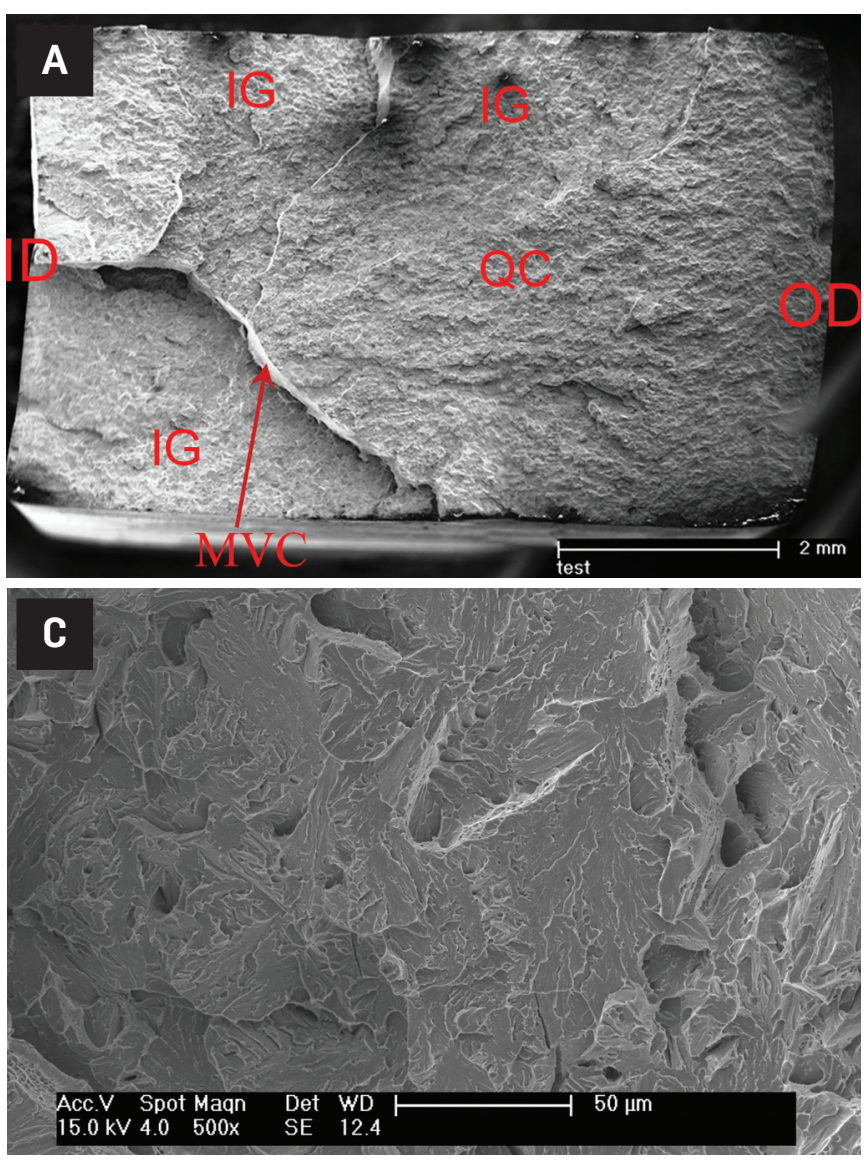
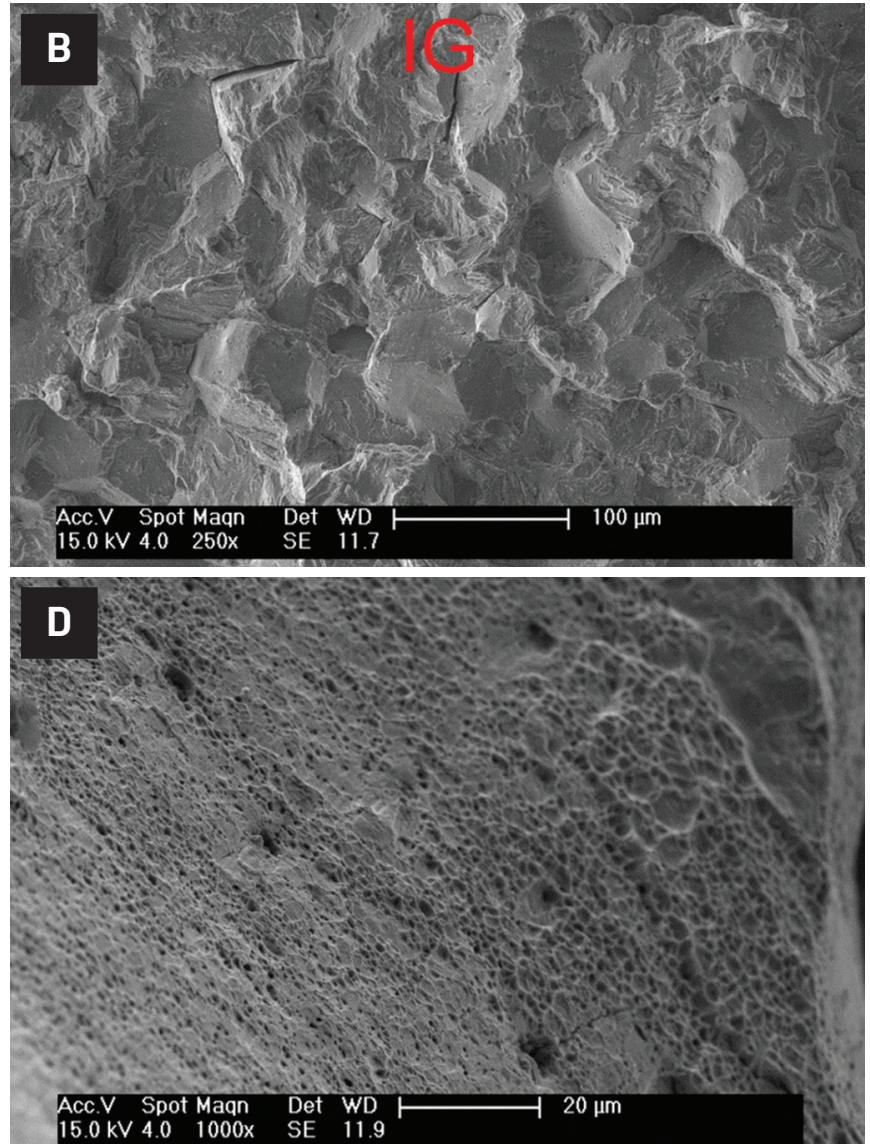

Fig. 9 - Fractography analysis of the simulated CGHAZ charged from all four sides: A - Macro image; B - intergranular failure mode close to the machined side; $C$ - quasi-cleavage failure mode in the middle of the sample; $D$ - microvoid coalescence on the ridge between cracks.

the circuit back to the power supply. The tubes running into the top and side of the cell were used to circulate the charging solution, and the tube running out of the bottom allowed for evacuation of the fluid at the end of a test.

The Grade T24 base metal and its simulated CGHAZ samples were tested using the DHCT. The samples were charged through only the gauge-section ID surface or the full-gaugesection circumference (all four sides). The samples that were charged only through the ID simulated the actual service condition for the tube (only the ID surface was exposed to the hydrogen-containing environment), while charging through the full circumference exposed the microstructure in the bulk of the tube wall to the hydrogen-containing environment. This was done to simulate the direct exposure of the CGHAZ microstructure to the tube environment in case the decarburized layer at the ID was removed during the preweld groove preparation. This approach allowed for comparison of the HAC susceptibility of the T24 steel base metal and simulated CGHAZ, as well as evaluation of the effect of the decarburized zone at the tube ID on the HAC susceptibility.

A simulated CGHAZ sample was charged with hydrogen from the ID for $48 \mathrm{~h}$ without mechanical loading to identify the preferential crack initiation locations. Another simulated CGHAZ sample was loaded at $90 \%$ of the steel yield strength for $264 \mathrm{~h}$ without hydrogen charging to provide a base line.

\section{Fractography Analysis and Microstructure Characterization}

The fracture surface of the failed test samples was analyzed using a Philips ESEM FEG-30 SEM. An optical microscope was used for metallurgical analysis of the samples. The samples were cut parallel to the loading direction, showing both the fracture surface (if present) and the OD and ID surfaces. They were then mounted in conductive Bakelite, ground, polished, and etched with $5 \%$ nital.

For the nonfailure samples, the charged area was cut from the sample and mounted on a stub for SEM examination. These samples were also cross sectioned in the charged area and mounted, ground, polished, and etched using 5\% nital. They were then examined using an optical microscope and SEM to evaluate the effect of hydrogen charging on the microstructure. Microhardness measurement was performed on the cross sections of the base metal and simulated CGHAZ using a 100-g load.

\section{Results and Discussion}

\section{DHCT Results}

The DHCT results are summarized in Table 2. The base metal samples that were charged only through the ID and 

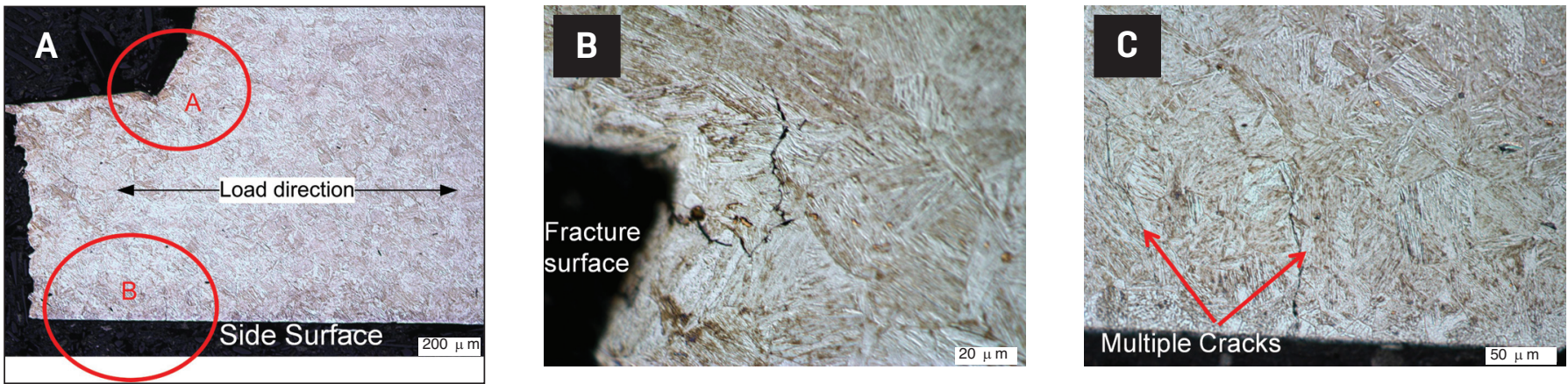

Fig. 10 - Cross section of the simulated CGHAZ charged from all four sides with loading: A - Low-magnification image; B higher-magnification image of region $A ; C$ - higher-magnification image of region $B$.

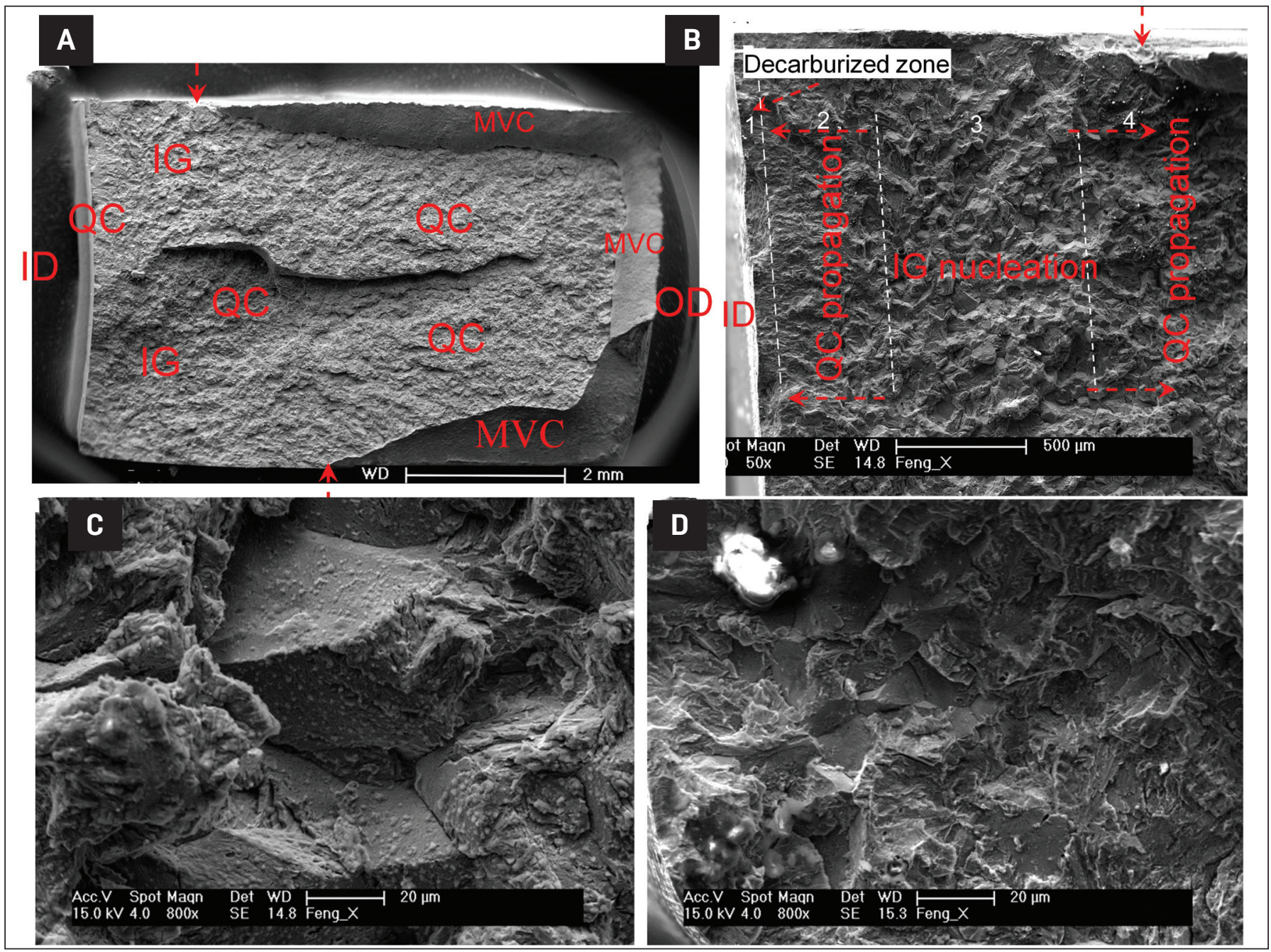

Fig. 11 - Fractography analysis of the simulated CGHAZ charged from the ID: A - Macro image; B - higher-magnification image on the ID side; $C$ - higher-magnification image of IG; $D$ - higher-magnification image of $Q C$ in the decarbonized zone.

through all four sides did not fail after 266 and $672 \mathrm{~h}$, respectively. The CGHAZ only with charging did not fail but showed cracks after 48-h charging. The CGHAZ only with loading did not fail after $264 \mathrm{~h}$. However, all the chargedsimulated CGHAZ samples with loading failed. The chart of time to failure for these samples are shown in Fig. 8. It was found that the decarburized layer on the ID tube surface had a significant effect on the time to failure in Grade T24 steel samples. Samples charged only through the ID surface failed in about $4 \mathrm{~h}$, while samples charged through the whole circumference of the gauge section (ID, OD, and two machined sides) failed in about $2 \mathrm{~h}$.

\section{Fractography Analysis}

Figure 9 shows the fractography analysis result of the 


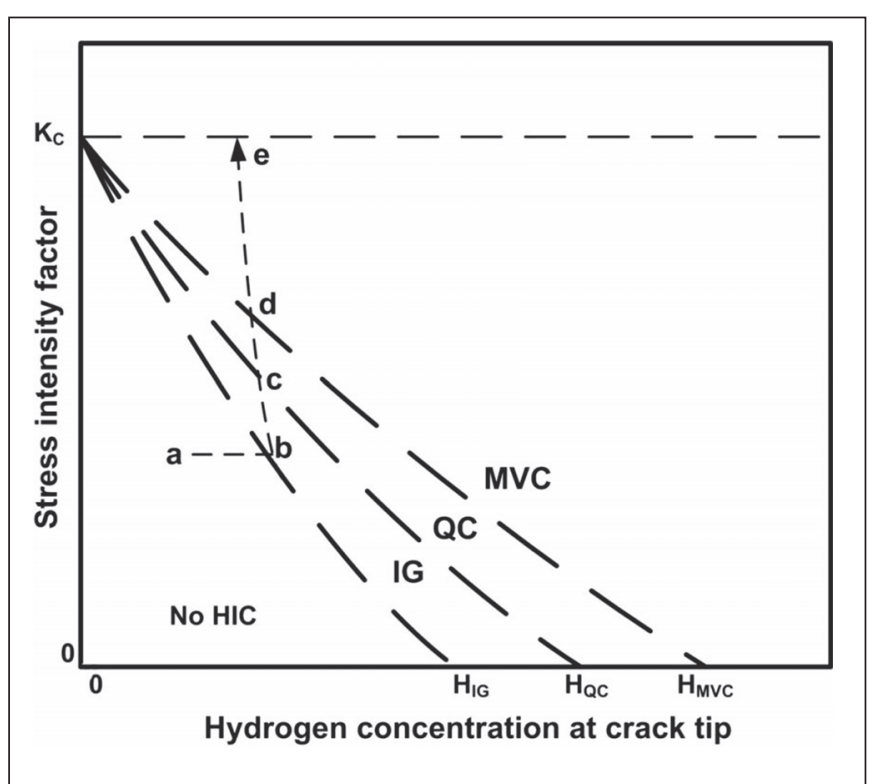

Fig. 12 - Beachem's hydrogen-induced cracking model (Ref. 22).

simulated CGHAZ sample charged from all sides with loading. Because the two samples show similar fracture surface features, fractography analysis of only one of the two samples (sample T24 CGHAZ 2) is shown here. Intergranular (IG) failure was observed on the two machined sides of the sample. These locations should be the crack initiation in this sample. The cracks propagated in a quasi-cleavage (QC) mode. Where these cracks met, microvoid coalescence (MVC) was found. Because the sample was charged from all sides, more hydrogen could get into the sample in the same time compared to the sample that was only ID charged. Therefore, the time to failure of the all-sides-charged samples $(\sim 2 \mathrm{~h})$ was shorter than that of the only-ID-charged samples $(\sim 4 \mathrm{~h})$.

Figure 10 shows the longitudinal direction of the failed sample, which was charged from all sides with loading. Secondary cracks were found along the fracture surface. $\mathrm{Ti}(\mathrm{C}$, $\mathrm{N})$ particles were adjacent to the cracks. Multiple crack nucleations were observed in the CGHAZ. These cracks showed typical HAC features. This further proved the crack initiated from the two machined sides of the sample.

Figure 11 shows the fractography analysis of the simulated CGHAZ sample charged only from the ID. Because the two samples showed similar fracture surface features, fractography analysis of only one of the two samples (sample T24 CGHAZ ID 2) is shown here. In this sample, MVC was observed at the OD side and the two machined sides of the sample. A ductile ridge was present in the middle of the sample - Fig. 11A. An additional detailed analysis on the ID side is shown in Fig. 11B. This area can be divided into four regions - Fig. 11B. The very left region (region 1 ) was the ID decarburized zone, and the failure mode was QC. The second region (region 2) and fourth region (region 4 ) showed the QC mode. In between regions 2 and 4 was region 3 , which was the crack nucleation region exhibiting the IG mode. Higher magnification images of the IG mode in region 3 and the $\mathrm{QC}$ mode in region 1 are shown in Fig. $11 \mathrm{C}$ and D, respectively.
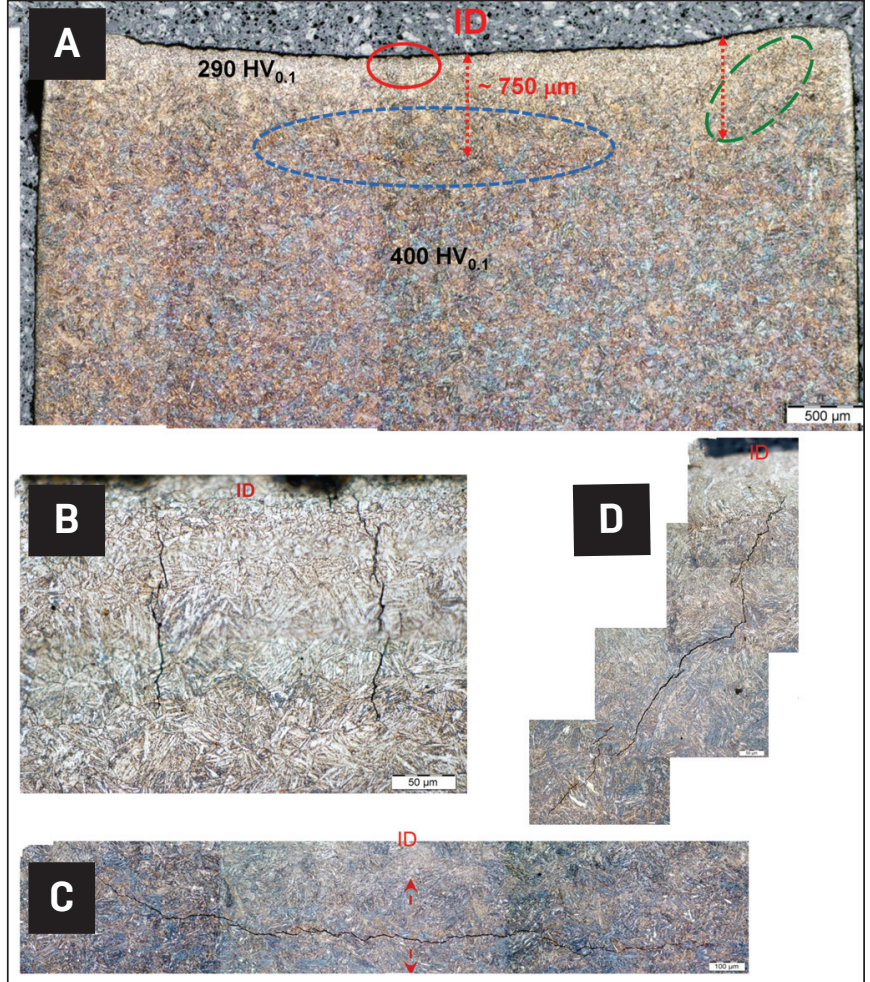

Fig. 13 - Microstructure of the charged-simulated CGHAZ without loading: $A$ - Macro image; $B$ - cracks in the decarbonized zone; $C$ - cracks parallel to the ID surface; $D$ cracks diagonal from the ID surface.

Based on the fractography analysis, the HAC mechanism was explained with Beachem's model (Ref. 22) - Fig. 12. The microstructure in the decarburized zone was ferrite, which was resistant to HAC. Because the diffusion rate of hydrogen in ferrite is high, but the solubility of hydrogen in ferrite is low, the hydrogen diffused into the martensite (region 3 in Fig. 11B) very fast through the decarburized zone. When hydrogen accumulates to a critical level in the martensitic microstructure, an IG crack will initiate (point b in Fig. 12). After the crack initiates, the stress intensity in front of the crack sharply increases and less hydrogen is needed for the crack to propagate. The failure propagated in the IG mode through region 3 , which had a relatively high hydrogen concentration (line b-c in Fig. 12). With the crack propagating, the stress intensity further increased to a level that an even lower hydrogen concentration was needed for the crack to continue growing (point $\mathrm{c}$ in Fig. 12). The hydrogen concentration in regions 1 and 4 was decreased due to the lower hydrogen solubility in region 1 and the insufficient charging time in region 4 . The combination of lower hydrogen concentration and higher stress intensity in regions 1 and 4 resulted in cleavage crack propagation (line c-d in Fig. 12).

With further increase of the stress intensity, the failure mode transitioned to ductile failure (MVC mode), which was observed in the two machined sides and OD side (line $d-e$ in Fig. 12). The reason for the ductile ridge in the middle of the tested sample could be that two main cracks nucleated and propagated separately and connected by a shear mechanism at the final stage of failure. 

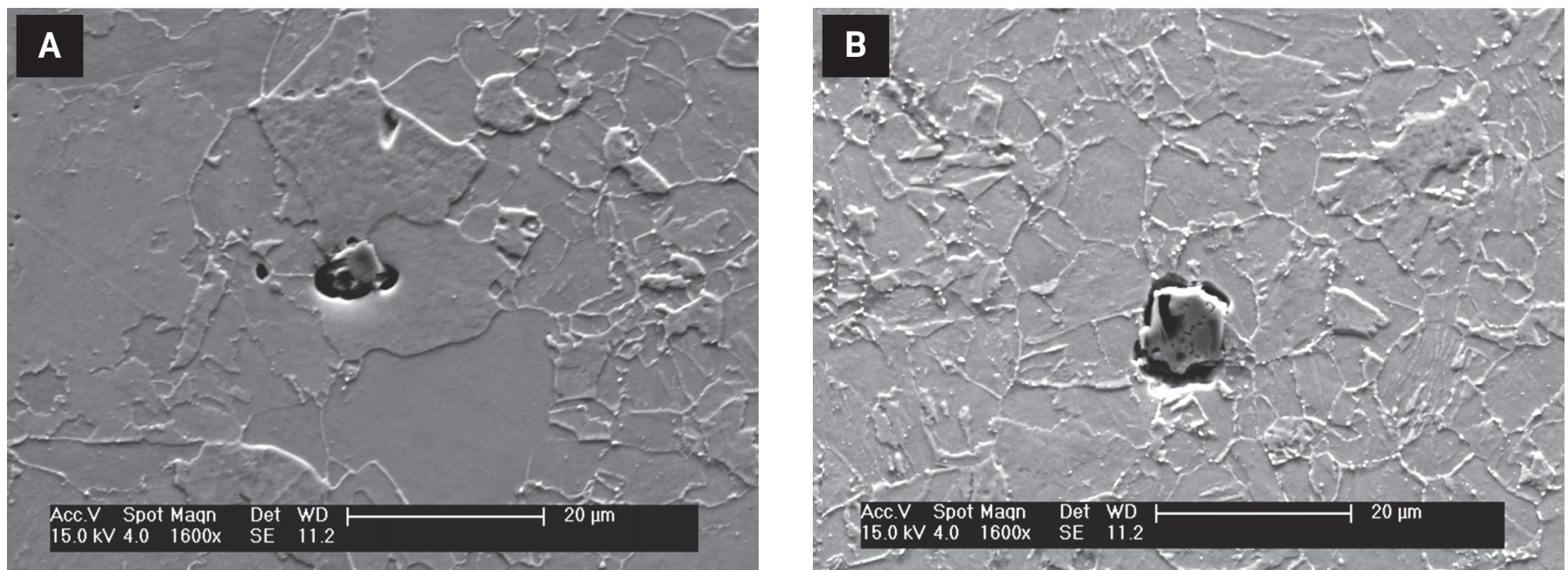

Fig. 14 - Microstructure of the decarbonized zone and bulk material of the base metal (charged from ID): A - Decarbonized zone; B - bulk material.
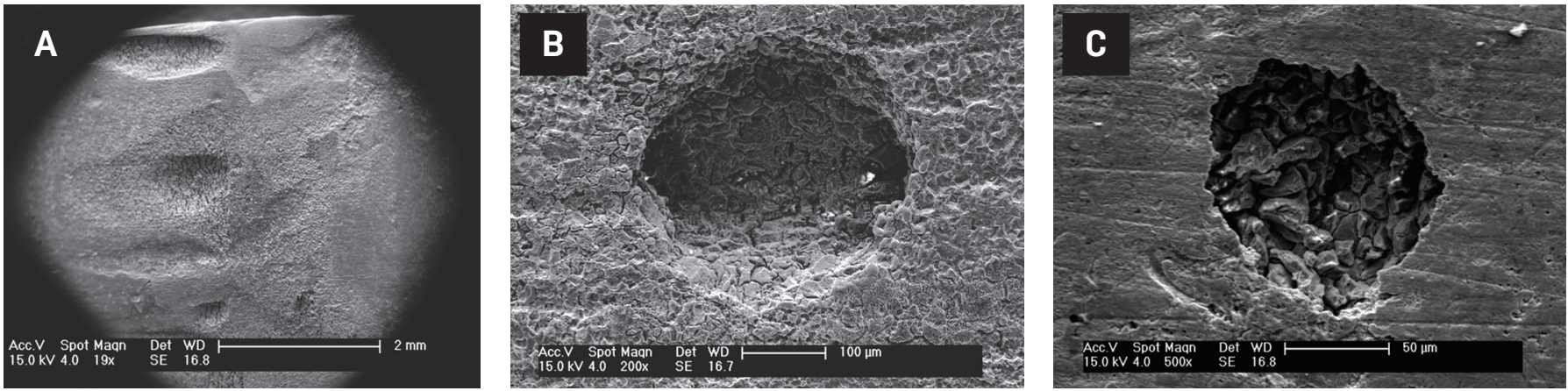

Fig. 15 - SEM image of the OD, ID, and machine side of the base metal (charged from all four sides): $A-O D$ surface; $B$ - ID surface; $c$ - machined side.

\section{Microstructure of the Nonfailed Samples}

Figure 13A-D shows the cross section of the charged, simulated CGHAZ sample without loading. Three cracks were found at different locations. The first one (Fig. 13B) was perpendicular to the ID surface and through the decarburized zone to the simulated CGHAZ. Compared with the CGHAZ, the hydrogen diffusion rate in the decarburized zone was higher, but the hydrogen solubility was lower. Therefore, it is possible that the crack nucleated in the CGHAZ and propagated back into the decarburized zone. The second crack (Fig. 13C) was in the CGHAZ and parallel to the ID surface. This crack propagated in a combination of intergranular, transgranular interlath, and branching modes. The third crack (Fig. 13D) was diagonal from the ID surface and propagated through the decarburized zone and simulated the CGHAZ. It showed similar propagation features as the second one. This confirmed the crack-initiation location in the DHCT samples.

Figure 14 shows the microstructure in the decarburized zone and the bulk of the DHCT base metal, which was charged from the ID and did not fail during the test. The decarburized zone had a larger grain size compared to the bulk material. $\operatorname{Ti}(C, N)$ particle surrounded by voids was observed in both the decarburized zone and the bulk material. No cracking was found in the decarburized zone or the bulk material. This indicated the base metal was more resistant to
HAC than the CGHAZ.

Figure 15 shows the SEM images of OD, ID, and one machined side of the base metal, which was charged from all four sides. Cavities were present on the ID surface and machined side but not on the OD surface. These could be hydrogen blisters, which could be caused by hydrogen accumulation around inclusions.

\section{Conclusions}

The susceptibility to HAC of the Grade T24 steel base metal and simulated CGHAZ was evaluated using the DHCT. The conclusions are summarized as follows:

1. The DHCT is capable of evaluating the effect of microstructure on the HAC susceptibility of Grade T24 steel welded joints.

2. No failure or cracking in the base metal of Grade T24 steel occurred for up to $672 \mathrm{~h}$ under the testing condition. The time to failure of the CGHAZ was about $2 \mathrm{~h}$ for when all four sides were charged and $4 \mathrm{~h}$ for only ID charging.

3. The difference in HAC susceptibility arise from the microstructure. The base metal has a tempered bainiticmartensitic microstructure, while the CGHAZ has an untempered martensite microstructure. The later has higher microhardness, leading to a higher HAC susceptibility.

4. The presence of the decarburized layer at the tube ID 
surface delayed the development of critical hydrogen concentration in the CGHAZ. This improved the resistance to $\mathrm{HAC}$, indicated by the longer time to failure when only charged from the ID surface compared to being charged from all four sides.

5. Fracture analysis showed the crack initiated on the sides without the decarburized layer. This further proved the decarburized layer was beneficial to the HAC resistance.

6 . In both charging conditions, the crack initiated with IG, then propagated with QC and ended with MVC. This fracture behavior was explained using Beachem's model.

\section{References}

1. Vaillant, J. C., Vandenberghe, B., Hahn, B., Heuser, H., and Jochum, C. 2008. T/P23, 24, 911 and 92: New grades for advanced coal-fired power plants - Properties and experience. International Journal of Pressure Vessels and Piping 85(1-2): 38-46. DOI: 10.1016/ j.ijpvp.2007.06.011

2. Golanski, G., Jasak, J., and Slania, J. 2014. Microstructure, properties and welding of T24 steel-critical review. Kovove Materialy 52(52): 99-106. DOI: 10.4149/km2014299

3. Bendick, W., Gabrel, J., Hahn, B., and Vandenberghe, B. 2007. New low alloy heat resistant ferritic steels T/P23 and T/P24 for power plant application. International Journal of Pressure Vessels and Piping 84(1-2): 13-20. DOI: 10.1016/j.ijpvp.2006.09.002

4. Coleman, K. K., and Newell Jr., W. F. 2007. P91 and beyond. Welding Journal 86(8): 29-33.

5. Lalik, S., Niewielski, G., and Cebulski, J. 2006. Mechanical properties of joints welded in creep-resistant low-alloy T24 steel. Welding International 21(5): 364-367. DOI: 10.1080/ 09507110701455533

6. David, S. A., Siefert, J. A., and Feng, Z. 2013. Welding and weldability of candidate ferritic alloys for future advanced ultrasupercritical fossil power plants. Science and Technology of Welding and Joining 18(8): 631-651. DOI: 10.1179/1362171813Y.0000000152

7. Rhode, M., Steger, J., Boellinghaus, T., and Kannengiesser, T. 2016. Hydrogen degradation effects on mechanical properties in T24 weld microstructures. Welding in the World 60(2): 201-216. DOI: $10.1007 / s 40194-015-0285-5$

8. DuPont, J., Siefert, J. A., and Shingledecker, J. P. 2017. Microstructural evolution and mechanical properties of Grades 23 and 24 creep strength enhanced ferritic steels. International Materials Reviews 62(1): 32-56. DOI: 10.1080/09506608.2016.1207008

9. Arndt, J., and Vallourec \& Mannesmann Tubes. 2000. The T23/T24 Book: New Grades for Waterwalls and Superheaters. Vallourec \& Mannesmann.

10. Bauné, E., Leduey, B., Bonnet, C. and Bertoni, A. 2004. Development of welding consumables dedicated to the welding of new generation 21/4Cr-1Mo pipe materials P23 and P24 for power generation and hydrogen service. Proc. European Symposium on Pressure Equipment (ESOPE 2004). Paris, France: Association Française des Ingénieurs en Appareils à Pression (A.F.I.A.P.)

11. Huysmans, S., Vanderlinden, F., and De Bruycker, E. May 2013. Weldability aspects of T24 boiler tubing in the context of stress corrosion cracking. ETD Seminar, pp. 2-5. London, UK.

12. Ullrich, C., Heckmann, S., Tillmann, W., Bodmer, T., and Gierschner, G. 2013. Stress corrosion cracking of T24 - Service experience and investigation program. ETD Seminar, pp. 2-4. London, UK.

13. Dhooge, A., and Vekeman, J. 2005. New generation $2.25 \mathrm{Cr}$ steels T/P 23 and T/P 24 weldability and high temperature properties. Welding in the World 49(9-10): 31-49. DOI: 10.1007/ bf03266492
14. Nowack, R., Götte, C., and Heckmann, S. 2011. Quality management at RWE using T24 boiler material as an example. VGB PowerTech Journal 11: 1-5.

15. Yue, X., and Lippold, J. C. 2013. Evaluation of heat-affected zone hydrogen-induced cracking in navy steels. Welding Journal 92(1): 20-s to 28-s.

16. Savage, W. F., Nippes, E. F., and Homma, H. 1976. Hydrogen induced cracking in HY-80 steel weldments. Welding Journal 55(11): 368-s to 376-s.

17. Devletian, J. H., and Fichtelberg, N. D. 2001. Controlling hydrogen cracking in shipbuilding. Welding Journal 80(11): 46-s to 52-s.

18. Mayudeeswaran, G., Balasubramanian, V., and Reddy, G. M. 2008. Hydrogen induced cold cracking studies on armour grade high strength, quenched and tempered steel weldments. International Journal of Hydrogen Energy 33(7): 1897-1908. DOI: 10.1016/ j.ijhydene.2008.01.035

19. Okuda, N., Ogata, Y., Nishikawa, T., Aoki, A., Goto, A., and Abe, T. 1987. Hydrogen-induced cracking susceptibility in highstrength weld metal. Welding Journal 66(5): 141-s to 146-s.

20. Paddea, S., Masuyama, F., and Shibli, A. 2014. Coal Power Plant Materials and Life Assessment, pp. 87-106. Woodhead Publishing. DOI: 10.1016/c2013-0-16254-x

21. Alexandrov, B. T., Shi, S., Rodelas, J. M., and Lippold, J. C. March 2012. C2012-0001602 A new test for evaluation of susceptibility to hydrogen assisted cracking in dissimilar metal welds. 2012 NACE Conference Papers: 1-11. NACE International.

22. Beachem, C. D. 1972. A new model for hydrogen-assisted cracking (hydrogen "embrittlement"). Metallurgical Transactions 3(2): 441-455. DOI: 10.1007/bf02642048

XIULI FENG (jasmineosu@gmail.com) is the welding team lead at Honeywell Aerospace, Los Angeles, Calif. JOSEPH M. STEINER, BOIAN T. ALEXANDROV, and JOHN C. LIPPOLD are with the Welding Engineering program, Department of Materials Science and Engineering, The Ohio State University, Columbus, Ohio.

\section{Authors: Submit Research Papers Online}

Peer review of research papers is managed through an online sytem using Editorial Manager software. Papers can be submitted into the system directly from the Welding Journal page on the AWS website (aws.org) by clicking on "submit papers." You can also access the site directly at editorialmanager.com/wj/. Follow the instructions to register or log in. This online system streamlines the review process, and makes it easier to submit papers and track their progress. By publishing in the Welding Journal, more than 70,000 members will receive the results of your research.

Additionally, your full paper is posted on the American Welding Society website for FREE access around the globe. There are no page charges, and articles are published in full color. By far, the most people, at the least cost, will recognize your research when you publish in the world-respected Welding Journal. 